\title{
Relationship between Flower Opening in Six Cotton Cultivars and Their Progeny to Pollen Dehydration Tolerance
}

\author{
John J. Burke and Mauricio Ulloa \\ USDA-ARS Cropping Systems Research Laboratory, 3810 4th Street, Lubbock, TX 79415, USA \\ Correspondence should be addressed to John J. Burke; john.burke@ars.usda.gov
}

Received 18 January 2017; Accepted 10 April 2017; Published 11 May 2017

Academic Editor: Jutta Ludwig-Müller

Copyright ( 2017 John J. Burke and Mauricio Ulloa. This is an open access article distributed under the Creative Commons Attribution License, which permits unrestricted use, distribution, and reproduction in any medium, provided the original work is properly cited.

\begin{abstract}
Cotton (Gossypium hirsutum L.) production in arid and semiarid environments routinely experiences elevated temperature and low humidity challenges that ultimately determine yield and producer profitability. The present study investigated the diversity of flower petal opening to determine if traditional genetics and breeding approaches could develop a more cupped or closed flower, thereby providing a more humid microenvironment around the dehisced pollen. Six cultivars with reported differences in pollen humidity sensitivity were used to evaluate the genetics of petal opening. Crosses between open flower cultivars generally resulted in $\mathrm{F}_{1}$ offspring with open flowers. Crosses between closed flower cultivars generally resulted in $\mathrm{F}_{1}$ offspring with closed flowers. Crosses between open and closed flower cultivars provided unique phenotypes depending on the cultivars used. The results from the $\mathrm{F}_{1}$ offspring suggested that the male parent influenced the flower shape of the offspring. In addition, analysis of $\mathrm{F}_{2}$ offspring from the bidirectional crosses suggests that a single dominant gene from the male parent ultimately influences flower petal openness. Using traditional breeding techniques, it may be possible to develop cultivars with either open or closed flower phenotypes, linking pollen development stability and mature pollen viability across a range of environments to stabilize and enhance crop yield.
\end{abstract}

\section{Introduction}

Crop species grown throughout the world experience environmental stresses that limit their growth, development, and full expression of their genetic potential for agronomic yield. Comparison of average crop yields with reported record yields has shown that the major crops grown in the US exhibit annual average yields three- to sevenfold lower than record yields due to unfavorable environmental conditions [1]. Analysis of yields from corn (Zea mays L.), wheat (Triticum aestivum L.), soybean (Glycine max L.), sorghum (Sorghum vulgare L.), oat (Avena sativa L.), barley (Hordeum vulgare L.), potato (Solanum tuberosum L.), and sugar beet (Beta vulgaris L.) revealed that the average yield represented only $22 \%$ of the mean record yield. Crops with economically valuable reproductive structures showed the greatest discrepancy between average and record yields. Those crops having marketable vegetative structures exhibited approximately threefold reductions in yield [1]. These data suggest that plants have high productivity potential but are operating well below their genetic potential. Identifying and optimizing those plant protective mechanisms that could be used to improve stress-resistant germplasm stocks might lessen yield loss.

Cotton reproduction is strongly influenced by seasonal environmental conditions that determine yield potential and fiber quality [2-19]. Cotton flowers expand their petals the day before anthesis forming a shape commonly referred to as a "candle." The petals open the morning on which anthesis occurs and the petals close by the evening on the same day. Cotton pollen is composed of $50 \%$ water and is ready to germinate upon pollen release from the anthers [5]. Their hydration state aids in the rapid germination capacity of the pollen but also makes the pollen grain susceptible to dehydration in dry environments. A recent study concluded that, during the 15 -day periods both prior to and after initiation of an individual boll, evaporation, minimum relative humidity, and sunshine duration were the most significant climatic factors affecting cotton flower and boll production and retention in Egyptian cotton [20]. 
The negative correlation between each of evaporation and sunshine duration with flower and boll formation along with the positive correlation between minimum relative humidity value and flower and boll production indicated that low evaporation rate, short period of sunshine duration, and high value of minimum humidity would enhance flower and boll formation.

Genetic diversity in cotton pollen dehydration sensitivities has been identified among six cotton cultivars [5]. This diversity in pollen viability was observed following a $6.5 \mathrm{~h}$ exposure to $25 \%$ relative humidity (RH). NM67, DP565, and SG246 exhibited less inhibition of pollen germination than STV474, Acala Maxxa (AM), and PHY72. Similar pollen water contents were observed for all lines. Genetic diversity in pollen tube length development at $25 \% \mathrm{RH}$ compared with $80 \% \mathrm{RH}$ also was observed. AM and $\mathrm{PHY} 72$ pollen produced tube lengths of $35-40 \%$ of controls at $80 \% \mathrm{RH}$, while STV 474 , SG248, DP565, and NM67 exhibited tube lengths 50-60\% of controls. Pollen water uptake studies showed faster uptake in PHY72 and AM than the other lines. Competitive pollination showed faster germination of PHY72, AM, and SG248 pollen compared to STV474, DP565, and NM67. These findings show genetic differences in cotton pollen sensitivities to water uptake and water loss [5]. In addition, a recent study [4] investigated the impact of pollen sensitivity to low humidity on the amount of outcrossing to neighboring plants. Cotton cultivars with mature pollen sensitive to low humidity grown in a semiarid environment exhibited reduced outcrossing compared to cultivars that were less sensitive to low humidity.

This study investigated the flower shapes of these cotton cultivars to determine how open or closed the petals became during anthesis. Flowers with cupped petals would provide a more humid microenvironment compared to the flowers with completely open petals. The differences in microenvironments may impact the longevity of the pollen following dehiscence. Cultivar differences in the amount of petal opening are reported and initial findings on the genetic control of this trait are described.

\section{Materials and Methods}

2.1. Germplasm. New Mexico 67 (NM67) is a recombinant inbred line generated from the cross of NM24016 with TM-1, made in 1994 [21]. NM24016 is an inbred line with the interspecific pedigree, H12156/2/77-505/Russian 5904 [22]. Cultivars analyzed included Suregrow 248 (SG248), Stoneville 474 (STV474), Deltapine 565 (DP565), New Mexico 67 (NM67), Acala Maxxa (AM), and Phytogen 72 (PHY72).

2.2. Greenhouse Cultural Practices. SG248, STV474, DP565, NM67, AM, and PHY72 cotton seeds were planted into \#5 custom [30 cm diameter, 14.13 liter] pots (BWI Companies, Nash, TX) containing Sunshine Mix \#1 soil (Sun Gro Horticulture Distributors, Inc., Agawam, MA). Three seeds were planted per pot and pots were placed on benches in a greenhouse set to provide a $31 / 27^{\circ} \mathrm{C}$ day/night cycle. Plants were thinned to one plant per pot and grown throughout the year. $430 \mathrm{~W}$ high-pressure sodium lights (P. L. Light Systems,
TABLE 1: Cotton cultivars and populations evaluated for flower shape.

\begin{tabular}{lc}
\hline Cultivars & \multicolumn{1}{c}{ Populations } \\
\hline Stoneville 474 & $\mathrm{~F}_{2}$ Stoneville $474 \times$ Phytogen 72 \\
Suregrow 248 & $\mathrm{~F}_{2}$ Phytogen $72 \times$ Stoneville 474 \\
Deltapine 565 & \\
New Mexico 67 & \\
Acala Maxxa & \\
Phytogen 72 & \\
\hline
\end{tabular}

Beamsville, ON, Canada) were used to maintain a $16 / 8 \mathrm{~h}$ photoperiod. Nutrients were maintained by daily application with Peters Excel fertilizer (Scotts-Sierra Horticultural Products Company, Marysville, $\mathrm{OH}$ ) through the automated watering system.

2.3. Development of Populations. Pollen from Suregrow 248 (SG248), Stoneville 474 (STV474), Deltapine 565 (DP565), New Mexico 67 (NM67), Acala Maxxa (AM), and Phytogen 72 (PHY72) was collected and transferred to recipient flowers sterilized according to the procedure of Burke [23]. All possible cross-combinations were made and $\mathrm{F}_{1}$ seed was collected at maturity. In addition, two $\mathrm{F}_{2}$ populations were developed and derived from PHY72 $\times$ STV474 and STV474 $\times$ PHY72 $\mathrm{F}_{1}$ populations with 224 individuals each, 131 and 93 used in additional analyses, respectively. Cotton entries, $\mathrm{F}_{1}$ and $\mathrm{F}_{2}$ populations, used in this study are presented in Table 1.

2.4. Flower Opening Rating. Flowers were photographed between 10 am and 3 pm from four $F_{1}$ plants for each developed population-cross in the greenhouse. Flower opening was rated on a scale from 1 (open) to 4 (closed) (Figure 1). Thirty-six photographs per cross were ordered from most opened to most closed petals and scored for the level of opening. Some of these photographs are presented in the figures.

2.5. Pollen Sterility Rating. A pollen sterility rating was applied to plants exposed to $42^{\circ} \mathrm{C} / 29^{\circ} \mathrm{C}$ day/night temperatures in a greenhouse. The ratings used in the analysis were $1=100 \%$ fertile, $2=25 \%$ pollen sac nondehiscence, $3=50 \%$ nondehiscence, $4=75 \%$ nondehiscence, and $5=$ total sterility [21]. Mean values were obtained and are shown in Figure 2 along with the flower opening rating (OPFLRT).

2.6. Data Analysis. Entries and populations were grown in a complete randomized design in different tests with two $\mathrm{F}_{2}$ populations and $36 \mathrm{~F}_{1}$ populations. OPFLRT data were analyzed using SAS 9.4 PROC GLM. Mean separation was performed to compare the OPFLRT mean of entries and progeny using Waller (SAS Institute Inc., Cary, NC). Heritability estimates for the data were calculated by using the variance components from the analysis of variance, being hierarchal $\left(a-h^{2}=V_{G} / V_{G}+V_{G \times E}+V_{E}\right)$ in the $\mathrm{F}_{2}$ generation of the two populations (Ponzoni and James, 1978). In addition, the means of selected parents were used to assess whether 


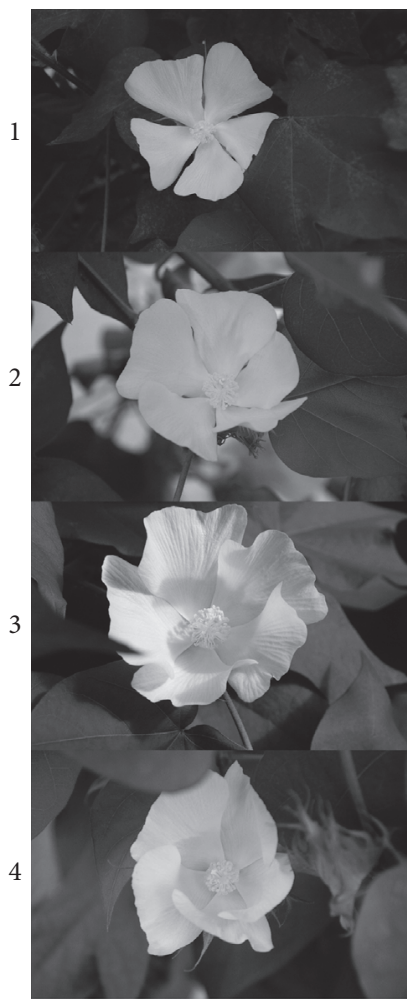

Figure 1: Photographs representing the range of flower petal opening evaluated in this study. A scale of 1 representing fully open petals to a scale of 4 representing highly cupped or closed petals was used in evaluating flower photographs.

actions of more than one-gene controlled OPFLRT. Observed ratios of open flower (OPFL), 1: heterozygote (HET), 2: closed flower (CLFL), 1; OPFL, 3: CLFL, 1; or CLFL, 3: OPFL, 1 were tested according to the one-gene model. Segregation data were tested for goodness of fit to predict Mendelian inheritance rations by chi-square test.

\section{Results}

Six cotton cultivars with diversity in drought tolerance and fiber quality were evaluated to better understand the phenotypic differences in the opening of the flower petals. STV474, SG248, and DP565 cultivars exhibit "open" or "nonoverlapping petal" flowers and NM67, AM, and PHY72 exhibit "closed" or "prominent petal overlapping" flowers (Figure 2). The open flowers expressed on STV474, SG248, and DP565 and the closed flowers expressed on NM67, AM, and PHY72 are expressed not only under greenhouse conditions but also under field conditions (data not shown). The images in Figure 2 are ordered from top to bottom based upon sterility indices (SI) determined for plants grown under a $42^{\circ} \mathrm{C} / 29^{\circ} \mathrm{C}$ day/night temperature regime. The cultivars with the lowest sterility indices were the STV474 (2.84) and SG248 (2.92). Sterility indices increased with the NM67 (3.46), PHY72 (3.67), and AM (3.77) cultivars. The DP565 exhibited the highest sterility index of 4.53. In addition, based on OPFLRT data AM, NM67 and PHY72 cultivars were rated as

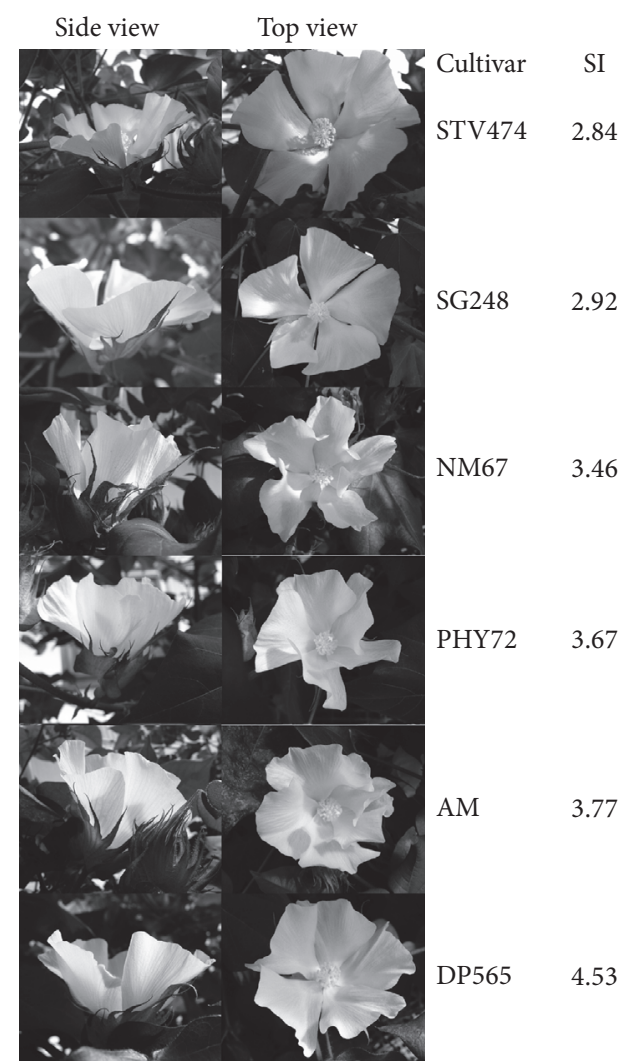

FIgURe 2: Photographs of the founder lines used in this study ordered from top to bottom based upon sterility indices (SI) determined for plants grown under a $42^{\circ} \mathrm{C} / 29^{\circ} \mathrm{C}$ day/night temperature regime.

CLFL from 2 to 4 values, while STV474, SG248, and DP565 were rated as OPFL with $<2$ values.

To shed light on the genetics behind the "open" and "closed" flower phenotypes, bidirectional crosses were made among the six cultivars (Table 1). Figure 3 is a montage of photographs of $\mathrm{F}_{1}$ plant flowers from the bidirectional crosses of the populations. The photographs represent the mean phenotype of all photographs of the $\mathrm{F}_{1}$ plants for each population. The female parent is represented at the top of the figure and the male parent is displayed to the left of the figure. Clear differences in flower phenotypes are apparent. To quantify the level of opening flower, we developed a rating (OPFLRT) scale shown in Figure 1. Flowers with fully separated petals were scored as 1 and the flowers with the most petal overlapping were scored as 4 .

The bidirectional crosses resulted in a continuum of flower shapes from the most open $\mathrm{F}_{1}$ flowers with a rating of 1.3 (NM67 X DP565) to the most closed flowers with a rating of 3.78 (AM X STV474) (Figure 4). Significant differences were observed among the developed $\mathrm{F}_{1}$ populations $(P<$ 0.05). Figure 5 shows the $F_{1}$ ratings and photographs of crossing open flower cultivars with other open flower cultivars. The average rating for these $F_{1} s$ was 2.2 (Figure 5 , horizontal line) with all crosses exhibiting the "open" flower phenotype. The ratings ranged from a low of 2.0 (STV474 X DP565) to a high 


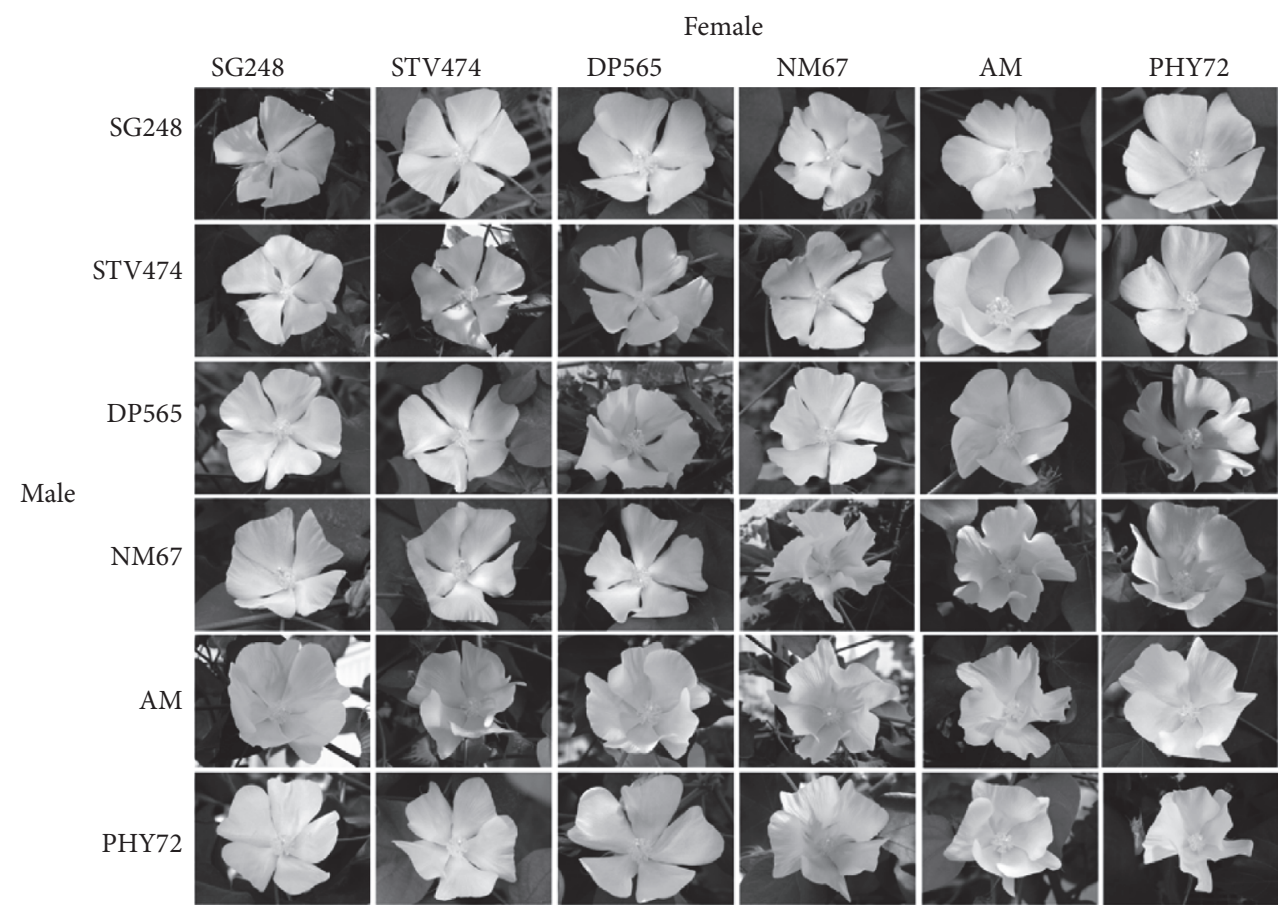

Figure 3: Photographs of $F_{1}$ plant flowers from the bidirectional crosses of the founder lines. The photographs represent the mean phenotype of all photographs of the $\mathrm{F}_{1}$ plants for each cross. The female parent is represented at the top of the figure and the male parent is displayed to the left of the figure.

of 2.43 (SG248 X DP565). No mean significant differences were observed among the developed $\mathrm{F}_{1}$ populations $(P<$ $0.05)$, except when they were compared with $F_{1}$ SG248 X DP565 population. Figure 6 shows the $\mathrm{F}_{1}$ ratings and photographs of crossing closed flower cultivars with other closed flower cultivars. The average rating for these $\mathrm{F}_{1} \mathrm{~s}$ was 3.04 (Figure 6, horizontal line) with all crosses except NM67 X AM (rating = 2.44) and PHY72 X NM67 (rating = 2.71) exhibiting the "closed" flower phenotype. The ratings ranged from a low of 2.44 (NM67 X AM) to a high of 3.413 (AM X PHY72). The NM67 X AM (rating $=2.44$ ) and PHY72 X NM67 (rating $=2.71$ ) were intermediate in their phenotype when compared to the average 2.2 rating of the open flower $F_{1} s$.

Crosses between cultivars with OPFL for the most part provided phenotypes that were primarily open, except for DP565 cultivar when it was used as male or female parent. Crosses between cultivars with CLFL provided for the most part phenotypes that were primarily closed, except when AM and NM67 cultivars were used as male or female parents. Mixes of phenotypes on some of the developed $F_{1}$ populations were observed, primarily resembling the second parent. In DP565 crosses, the average phenotype OPFLRT value was 2.32, with a minimum rating of 1.3 (NM67 X DP565) and a maximum rating of 3.05 (PHY72 X DP565). NM67 X DP565 (rating $=1.3$ ), STV474 X DP565 (rating $=2.0$ ), and DP565 X PHY72 (rating = 1.96) exhibited open phenotypes; AM X DP565 (rating = 2.5), SG248 X DP565 (rating = 2.43), DP565 X NM67 (rating $=2.41$ ), DP565 X SG248 (rating $=2.29)$, and DP565 X STV474 (rating $=2.29)$ exhibited open to intermediate phenotypes; and PHY72 X DP565
$($ rating $=3.05)$ and DP565 X AM (rating $=3.02)$ exhibited a more closed phenotype.

Crosses with Acala Maxxa generally resulted in a closed flower phenotype as evidenced by the average phenotype rating of 3.16 (horizontal line), with a minimum rating of 2.44 (NM67 X AM) and a maximum rating of 3.78 (AM X STV474). With the exception of NM67 X AM and AM X DP565, all of the other AM crosses resulted in flower phenotypes with ratings of three or above. In NM67 crosses, four $\mathrm{F}_{1}$ s exhibited the open phenotype (NM67 X DP565, NM67 X STV474, NM67 X AM, and STV474 X NM67), two $F_{1}$ s exhibited intermediate phenotypes (STV 474 X NM67 and PHY72 $\mathrm{X}$ NM67), and four $\mathrm{F}_{1} \mathrm{~s}$ exhibited closed phenotypes (NM67 X SG248, NM67 X PHY72, SG248 X NM67, and AM X NM67).

To further evaluate the genetic control and inheritance of flower shape, we developed two $\mathrm{F}_{2}$ populations, PHY72 X STV474 and its reciprocal STV474 X PHY72. These two cultivars were chosen as parents because they exhibited dramatically different flower phenotypes (Figures 1 and 2). Based on independent analyses of the $224 \mathrm{~F}_{2}$ plants in these two segregating populations, the $\mathrm{F}_{2}$ PHY72 X STV474 population had an average flower shape rating of 1.88 , and the $\mathrm{F}_{2}$ STV474 X PHY72 population had a rating of 2.31. Significant variation was observed among the plant individuals in each $\mathrm{F}_{2}$ population for open or closed flower shape using OPFLRT phenotype data. In addition, differences in OPFLRT phenotype data were observed between the two populations $(P<0.05)$. The heritability estimates for OPFLRT phenotype were observed to be moderate in the $\mathrm{F}_{2}$ PHY72 X STV474 


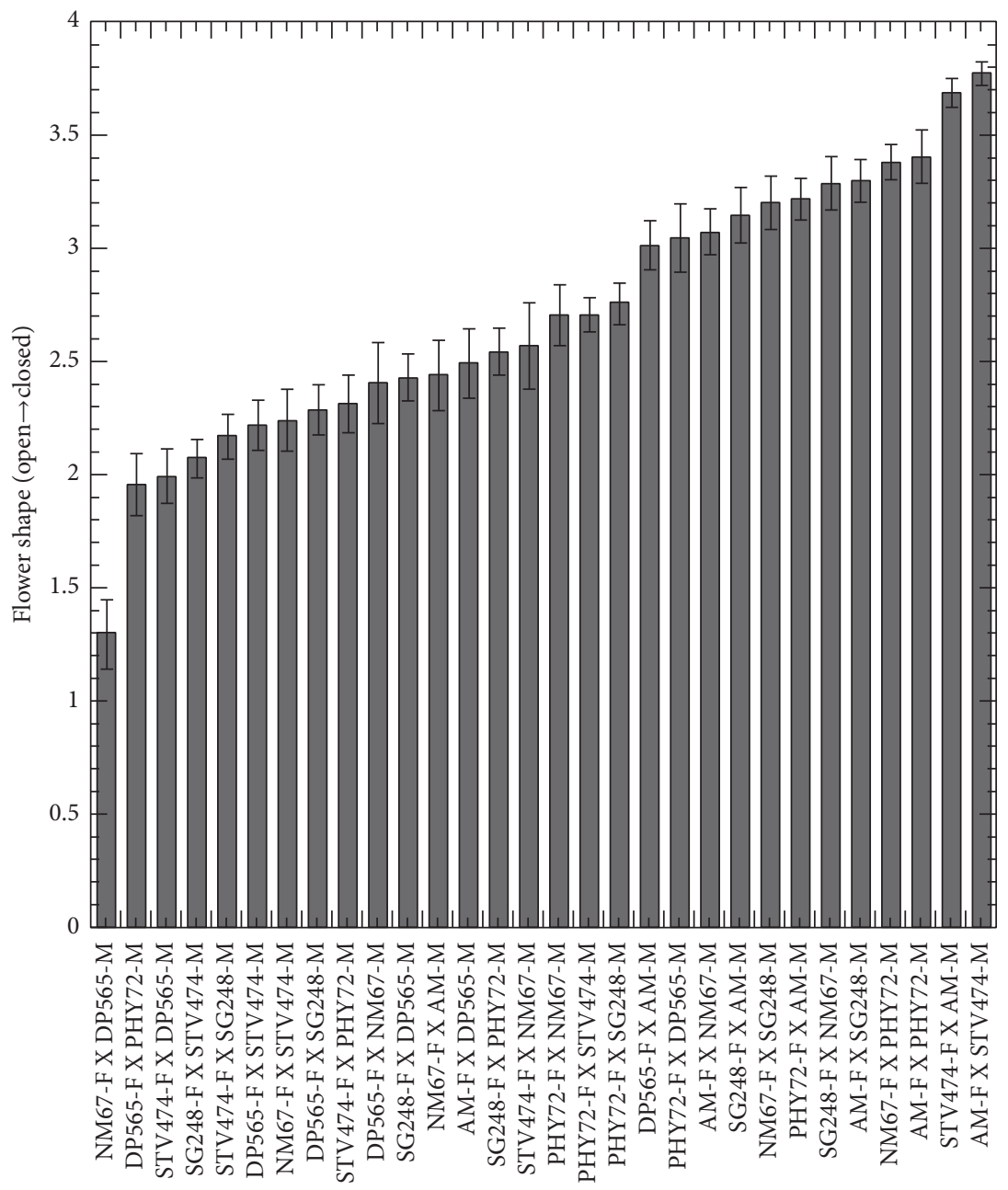

FIGURE 4: Graph showing the flower opening ratings from bidirectional crosses among all founder lines.

population $\left(a-h^{2}=0.45\right)$ with a tendency toward OPFL shape as the male parent STV474. The analysis of variance showed significant differences among plant-replicates in this population. The heritability estimates for OPFLRT phenotype were observed to be better in the $\mathrm{F}_{2}$ STV474 X PHY72 population $\left(a-h^{2}=0.69\right)$ with a tendency toward CLFL shape as the male parent PHY72. The analysis of variance showed no significant differences among plant-replicates in this population $(P<0.05)$.

Genetic analysis for one-gene model was also investigated for OPFLRT phenotype of these two $\mathrm{F}_{2}$ populations. The segregating data suggests a one-gene Mendelian inheritance model in these two populations (Table 2). Dominance gene action was observed for OPFL shape in the $\mathrm{F}_{2}$ PHY72 X STV474 population with 1 (OPFLRT scale $>2-4): 3$ (OPFLRT scale $\leq 2-1$ ), providing phenotypes primarily resembling the male parent (STV474) with OPFL shape. Also, dominance gene action was observed for CLFL shape in the $\mathrm{F}_{2}$ STV474 X PHY72 population with 1 (OPFLRT scale $<2$ 1) : 3 (OPFLRT scale $\geq 2-4$ ), providing phenotypes primarily resembling the male parent (PHY72) with CLFL shape. In these two $\mathrm{F}_{2}$ populations, dominance male-gene effect was observed for PHY72 (CLFL shape) and STV474 (OPFL shape) flower shape. However, modifications of dominance relationships were also observed on several $\mathrm{F}_{1}$ populations (Table 1 and Figure 4), especially, when DP565, NM67, and AM were used as parents in different cross-combinations. These additional populations provided evidence that, besides environmental effect, epistasis and more than one gene may be involved in the inheritance of flower shape in cotton. Additional research is needed to fully decipher the number of genes involved in this event.

\section{Discussion}

This study describes genetic diversity in degree of cotton flower petal opening that previously has not been described in the literature. The degree of cotton petal opening will impact the humidity levels around the dehiscing anthers, the temperature of the pollen when exposed to full sunlight [24], the pollen movement by pollinators, and possibly the accumulation of rain in the flower resulting in pollen rupture $[3,23]$. Based on analyses of parents, $F_{1}$ populations derived from bidirectional crosses of six cultivars, and two 
TABLE 2: Comparison of observed flower phenotypes and predicted segregation phenotypes for a dominant trait of $\mathrm{F}_{2}$ plants from bidirectional crosses between Phytogen 72 (PHY) and Stoneville 474 (STV) used as male (m) and female (f) parents.

\begin{tabular}{lcccc}
\hline Populations & Observed $<2-1$ & Observed $\geq 2-4$ & Predicted & Predicted \\
\hline $\mathrm{F}_{2}$ STVf $\times$ PHYm $^{\dagger}$ & 19 & 74 & 24 & 69 \\
$\mathrm{~F}_{2}$ PHYf $\times \mathrm{STVm}^{\ddagger}$ & 92 & 39 & 98 & 93 \\
\hline
\end{tabular}

Note: Mendelian inheritance rations for one gene for the test of goodness of fit, ${ }^{\dagger}$ open flower (OPFL) predicted 1 : closed flower (CLFL) predicted 3 and ${ }^{\ddagger}$ OPFL 3 : CLFL 1.
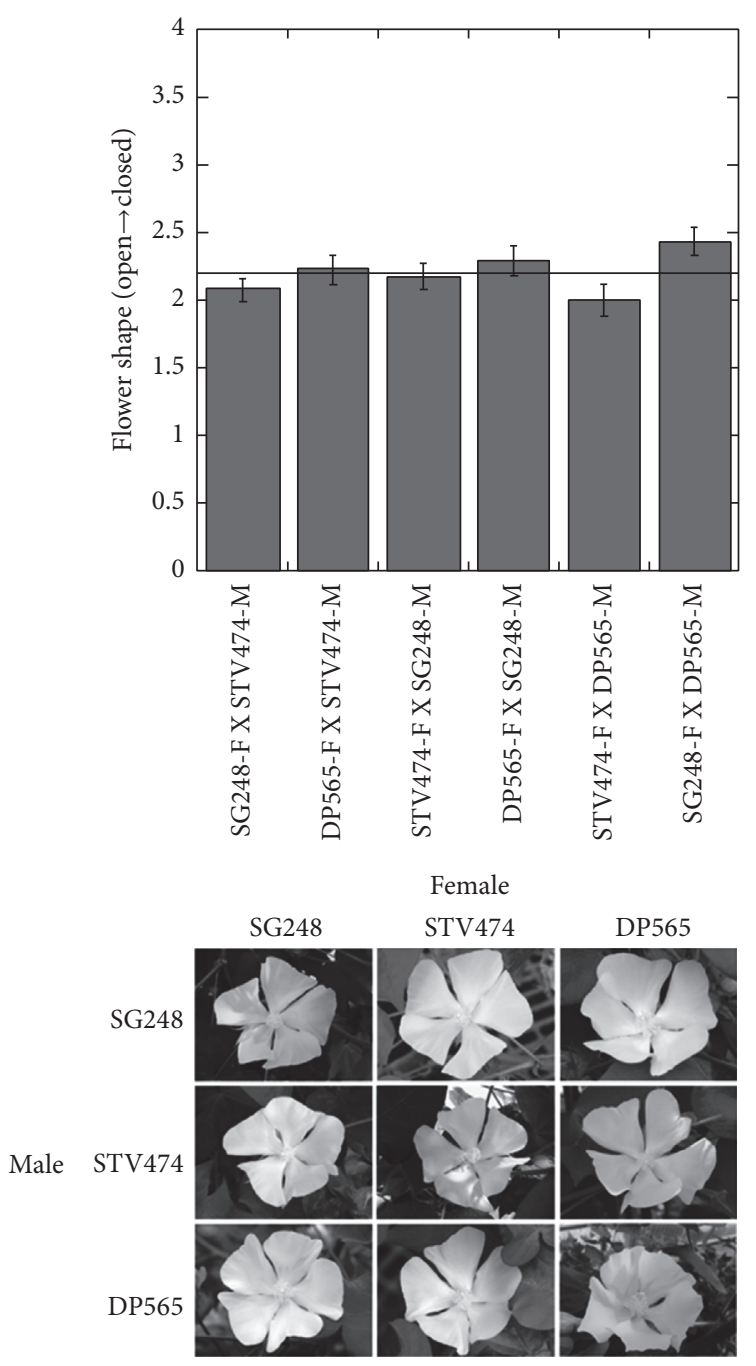

FIGURE 5: Photographs of observed flower phenotypes and a graph showing the $\mathrm{F}_{1}$ ratings of crossing among open flower cultivars. The average rating for these $\mathrm{F}_{1} \mathrm{~s}$ was 2.2 (horizontal line) with all crosses exhibiting the "open" flower phenotype.

$\mathrm{F}_{2}$ populations, it seems that flower shape or flower petal opening in cotton is genetically controlled with a Mendelian inheritance. However, some $\mathrm{F}_{1}$ populations also provided evidence that, besides environmental effect, epistasis and more than one gene may be involved in the inheritance of flower shape. The results from the $F_{1}$ offspring suggested that the male parent influenced the flower shape of the offspring. Analysis of $\mathrm{F}_{2}$ offspring from the bidirectional
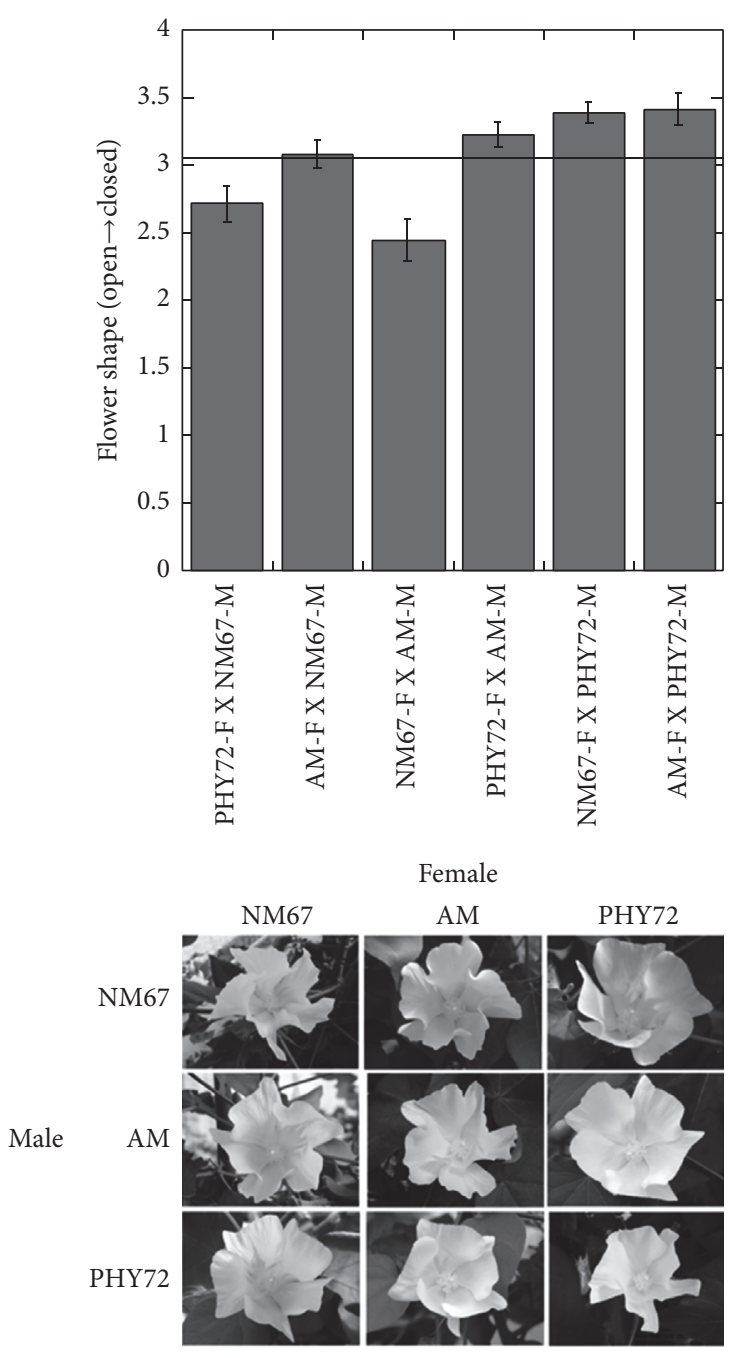

FIGURE 6: Photographs of observed flower phenotypes and a graph showing the $\mathrm{F}_{1}$ ratings of crossing among closed flower cultivars. The average rating for these $\mathrm{F}_{1} \mathrm{~s}$ was 3.16 (horizontal line) with all crosses exhibiting the "closed" flower phenotype.

crosses between Stoneville 474 and Phytogen 72 suggests that a single dominant gene from the male parent ultimately influences flower petal openness in these populations.

The open flower phenotypes observed among crosses between open flower cultivars (Figure 5) indicate a genetic control for petal opening. Similarly, the crosses between closed flower cultivars resulted in closed flower phenotypes (Figure 6), also supporting the concept of a similar genetic control point among these cultivars. However, some of the 
results of crosses among open and closed flower phenotypes provide a more complicated picture. Bidirectional crosses between DP565 and the other five cultivars generally produced offspring with a more open flower phenotype; however, the PHY72 X DP565 and DP565 X AM crosses resulted in closed phenotype flowers. Similarly, bidirectional crosses between AM and the other five cultivars generally produced offspring with a more closed flower phenotype. The exception was the NM67 X AM and AM X DP565 crosses. In addition, when NM67 (closed flower phenotype) was the female parent, open flower phenotypes were obtained with the exceptions of SG248 and PHY72. When NM67 was the male parent, DP565 and STV474 offspring exhibited open flower phenotypes, PHY72 exhibited an intermediate flower phenotype, and SG248 and AM exhibited the closed flower phenotype.

Segregation patterns of bidirectional crosses showed that flower shape of the offspring tended to track that of the male parent (Table 2). Analysis of the flowers exhibiting ratings below 2, and flowers with ratings from 2 to 4 , exhibited segregation ratios of $3: 1$ as would be predicted for a single dominant gene effect. The data suggests that the male parent carries the trait that will be passed on to the next generation. However, besides genetic control and possible epistatic effect, DP565, NM67, and AM cultivars have more complex pedigree, providing different levels of general or specific combining abilities when they are used as the male or female parent in diverse crosses. For example, NM67 is a recombinant inbred line arising from NM24016, classified as a stable G. hirsutum line with significant introgression from G. barbadense, and AM is also well known to possess introgression of G. barbadense. It is interesting to speculate that because NM67 and AM contain both G. hirsutum and G. barbadense introgressed genes, unique responses might be observed.

Our previous research on pollen humidity sensitivity [5] identified genetic diversity in the sensitivity of cotton pollen to low (25\%) humidity compared with higher $(80 \%)$ humidity. Two of the cultivars with pollen that were more tolerant to the $25 \% \mathrm{RH}$ treatment (STV474 and SG248) [5] had sterility indices of 2.84 and 2.92 and exhibited open flower shapes (Figure 2). The two cultivars with the pollen most sensitivity to low humidity (PHY72 and AM) had sterility indices of 3.67 and 3.77 and exhibited a more closed or cupped flower shape (Figure 2). The DP565 is an exception in that it has pollen very tolerant to low humidity [5] and an open flower shape by the highest sterility index observed in this study. It is important to understand that pollen biosynthesis and mature pollen viability are separate physiological responses. In plants, pollen biosynthesis has been shown to be very sensitive to abiotic and biotic stresses during pollen development [25]. Cotton flower sterility was reported for plants experiencing elevated temperatures 17 to 19 days prior to anthesis $[7,16,26]$. Genetic diversity for the sensitivity of cotton pollen development was reported [21]. Our findings also demonstrated genetic diversity in cotton pollen biosynthesis with sterility indices from greenhouse studies ranging from 2.84 to 4.53 (Figure 2). Reports of elevated temperature and low humidity sensitivities of mature cotton pollen $[5,9,24]$ also suggest that genetic diversity exists within modern cultivars. Additional research is ongoing to study the genetic diversity and genetic control and inheritance on pollen humidity sensitivity on these six cultivars and progeny and its relationship with flower shape.

It is interesting to hypothesize, from an evolutionary perspective, why flower petal opening would be linked to the male parent. One possibility could be related to the change of flowering plants in the reproduction process from cross-pollination or outbreeding, in which pollen tends to travel/move and experience more abiotic change/stress to self-pollination or selfing ("selfing syndrome"), in which pollen tends to be more confined/closed to the stigma [27]. Cotton is primarily a self-pollinated plant because of large, desiccation sensitive pollen grains [24]. However, natural outcrossing percentages have been reported in the $5-15 \%$ range $[4,28-30]$. Cotton cultivars with mature pollen grains sensitive to low humidity exhibited reduced outcrossing compared to cultivars that were less sensitive to low humidity [4]. An early report by Charnov [31] stated that pollen did not exist to ensure seed set, but as an equivalent means toward fitness gain to seeds. If flowers with cupped petals provide a more humid microenvironment than flowers with open petals, it is not unreasonable to hypothesize that transferring the trait for reducing flower petal opening would be evolutionarily advantageous for a plant with desiccation sensitive pollen in arid and semiarid environments.

\section{Conclusions}

Linking the traits of environmental tolerance of pollen biosynthesis, heat and humidity tolerance of mature pollen, and level of cotton flower openness may provide germplasm with significantly improved yield stabilities across environments. This study provides insights into the genetic control of cotton flower petal openness. Using traditional breeding techniques, it may now be possible to develop cultivars with either open or closed flower phenotypes. Linking this trait with pollen development stability and mature pollen viability across a range of humidities will enhance future yield levels and stability across environments.

\section{Disclosure}

Mention of a trademark, warranty, proprietary product, or vendor does not constitute a guarantee by the USDA and does not imply approval or recommendation of the product to the exclusion of others that may be suitable. USDA is an equal opportunity provider and employer.

\section{Conflicts of Interest}

The authors declare that there are no conflicts of interest regarding the publication of this paper.

\section{Acknowledgments}

The authors thank Jacob Sanchez and DeeDee Laumbach for their excellent technical support. The paper is funded in part by Cotton Incorporated Project no 5-703. 


\section{References}

[1] J. S. Boyer, "Plant productivity and environment," Science, vol. 218, no. 4571, pp. 443-448, 1982.

[2] P. W. Brown and C. A. Zeiher, "Cotton heat stress," in Cotton: A College of Agriculture Report, P-108, pp. 91-104, College of Agriculture, University of Arizona, Tucson, Ariz, USA, 1997.

[3] J. J. Burke, "Sprinkler-induced flower losses and yield reductions in cotton (Gossypium hirsutum L.)," Agronomy Journal, vol. 95, no. 3, pp. 709-714, 2003.

[4] J. J. Burke, "Genetic diversity of natural crossing in six cotton cultivars," Crop Science, vol. 56, no. 3, pp. 1059-1066, 2016.

[5] J. J. Burke, "Cotton flowers: pollen and petal humidity sensitivities determine reproductive competitiveness in diverse environments," in Cotton Physiology, D. M. Oosterhuis, Ed., pp. 25-36, Cotton Foundation, Cordova, Tenn, USA, 2011.

[6] R. G. Cantrell, M. Ulloa, R. Percy, E. Zeiger, and Z. Lu, "Genetic variation for stomatal conductance in an interspecific cotton population," in Proceedings of the Beltwide Cotton Conferences, vol. 1, pp. 485-486, 1998.

[7] W. D. Fisher, "Heat induced sterility in upland cotton," in Proceedings of the Beltwide Cotton Production Research Conferences, p. 85, 1975.

[8] G. Guinn, "Boll abscission in cotton," in Crop Physiology: Advancing Frontiers, U. S. Gupta, Ed., pp. 177-225, 1984.

[9] V. G. Kakani, K. R. Reddy, S. Koti et al., "Differences in in vitro pollen germination and pollen tube growth of cotton cultivars in response to high temperature," Annals of Botany, vol. 96, no. 1, pp. 59-67, 2005.

[10] D. A. Pennington, "Effect of sprinkler irrigation on open cotton flowers," in Proceedings of the Beltwide Cotton Production Research Conferences, pp. 69-71, 1987.

[11] W. T. Pettigrew, "The effect of higher temperatures on cotton lint yield production and fiber quality," Crop Science, vol. 48, no. 1, pp. 278-285, 2008.

[12] K. R. Reddy, G. H. Davidonis, A. S. Johnson, and B. T. Vinyard, "Temperature regime and carbon dioxide enrichment alter cotton boll development and fiber properties," Agronomy Journal, vol. 91, no. 5, pp. 851-858, 1999.

[13] K. R. Reddy, H. F. Hodges, and J. M. McKinion, "Carbon dioxide and temperature effects on pima cotton growth," Agriculture, Ecosystems \& Environment, vol. 54, pp. 17-29, 1995.

[14] K. R. Reddy, H. F. Hodges, J. M. McKinion, and G. W. Wall, "Temperature effects on pima cotton growth and development," Agronomy Journal, vol. 84, pp. 237-243, 1992.

[15] K. R. Reddy, H. F. Hodges, and V. R. Reddy, “Temperature effects on cotton fruit retention," Agronomy Journal, vol. 84, pp. 26-30, 1992.

[16] P. Sarvella, "Environmental influences on sterility in cytoplasmic male-sterile cottons," Crop Science, vol. 6, pp. 361-364, 1966.

[17] Z. M. Sawan, "Cotton (Gossypium barbadense) production as affected by climatic factors and soil moisture status," Acta Ecologica Sinica, vol. 32, no. 3, pp. 123-137, 2012.

[18] Z. M. Sawan, "Response of flower and boll development to climatic factors in Egyptian cotton (Gossypium barbadense)," Climatic Change, vol. 97, no. 3, pp. 553-591, 2009.

[19] J. L. Snider, D. M. Oosterhuis, B. W. Skulman, and E. M. Kawakami, "Heat stress-induced limitations to reproductive success in Gossypium hirsutum," Physiologia Plantarum, vol. 137, no. 2, pp. 125-138, 2009.
[20] Z. M. Sawan, "Statistical study: nature relationship between climatic variables prevailing prior to flowering or subsequent to boll setting and cotton production," Natural Science, vol. 6, no. 8, pp. 583-596, 2014.

[21] R. G. Percy, O. L. Mayo, M. Ulloa, and R. G. Cantrell, “Registration of AGC85, AGC208, and AGC375 upland cotton germplasm lines," Crop Science, vol. 46, no. 4, pp. 1828-1829, 2006.

[22] R. G. Cantrell and D. D. Davis, "Registration of NM24016, an interspecific-derived cotton genetic stock," Crop Science, vol. 40, p. 1208, 2000.

[23] J. J. Burke, "Moisture sensitivity of cotton pollen: an emasculation tool for hybrid production," Agronomy Journal, vol. 94, no. 4, pp. 883-888, 2002.

[24] J. J. Burke, J. Velten, and M. J. Oliver, "In vitro analysis of cotton pollen germination," Agronomy Journal, vol. 96, no. 2, pp. 359368, 2004.

[25] N. De Storme and D. Geelen, "The impact of environmental stress on male reproductive development in plants: biological processes and molecular mechanisms," Plant, Cell \& Environment, vol. 37, pp. 1-18, 2014.

[26] V. G. Meyer, "Some effects of genes, cytoplasm, and environment on male sterility of cotton (Gossypium)," Crop Science, vol. 9, pp. 237-242, 1969.

[27] A. Sicard, N. Stacey, K. Hermann et al., "Genetics, evolution, and adaptive significance of the selfing syndrome in the genus capsella," Plant Cell, vol. 23, no. 9, pp. 3156-3171, 2011.

[28] M. Afzal and A. H. Khan, "Natural Crossing in Cotton in Western Punjab. II. Natural Crossing Under Field Conditions," Agronomy Journal, vol. 42, pp. 89-93, 1950.

[29] M. A. Elfawal, M. A. Bishr, and E. K. Hassoub, "Natural cross pollination in Egyptian cotton (Gossypium barbadense L.)," The Journal of Agricultural Science, vol. 86, no. 1, pp. 205-209, 1976.

[30] S. G. Stephens and M. D. Finkner, "Natural crossing in cotton," Economic Botany, vol. 7, no. 3, pp. 257-269, 1953.

[31] E. L. Charnov, The Theory of Sex Allocation, Princeton University Press, Princeton, NJ, USA, 1982. 

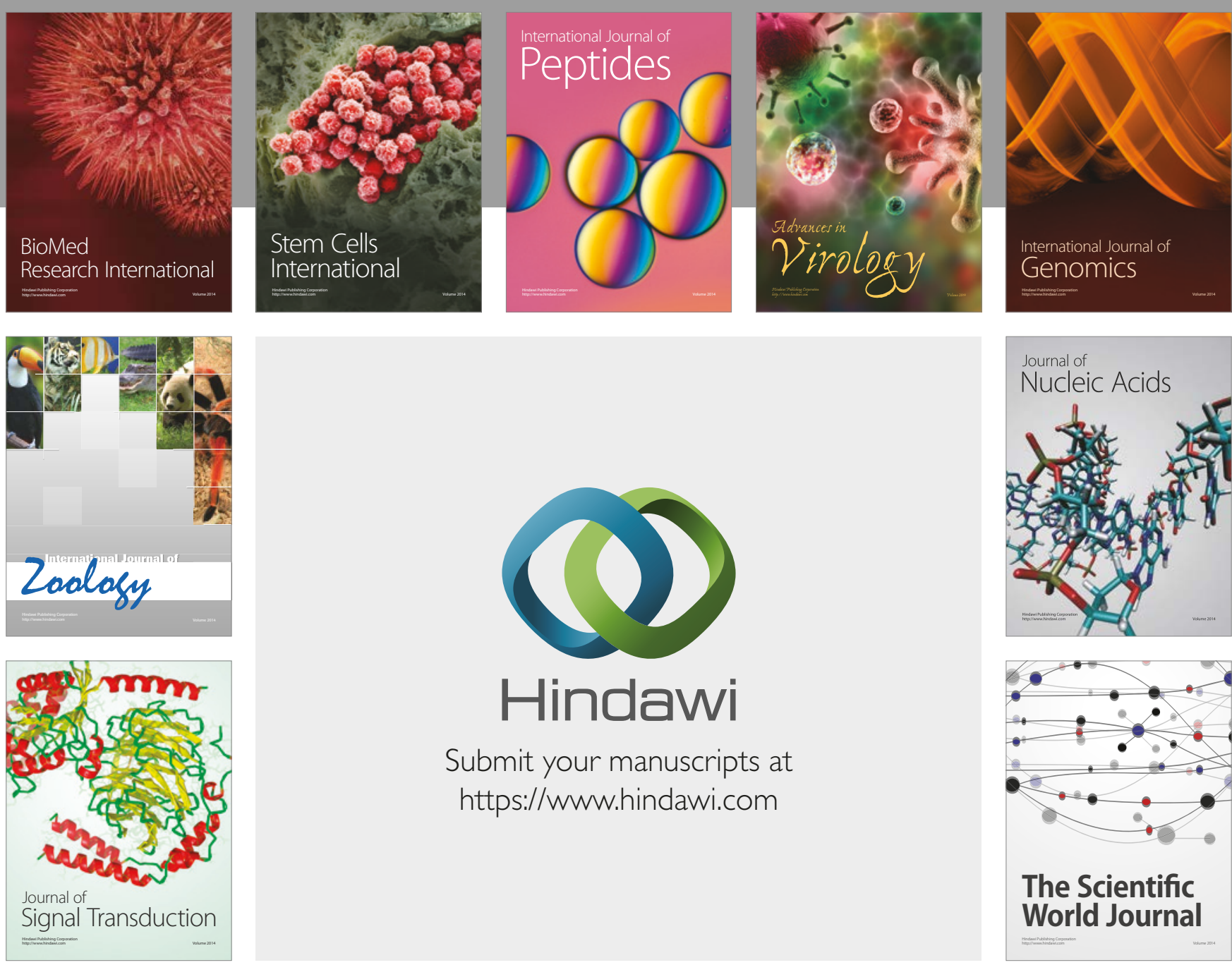

Submit your manuscripts at

https://www.hindawi.com
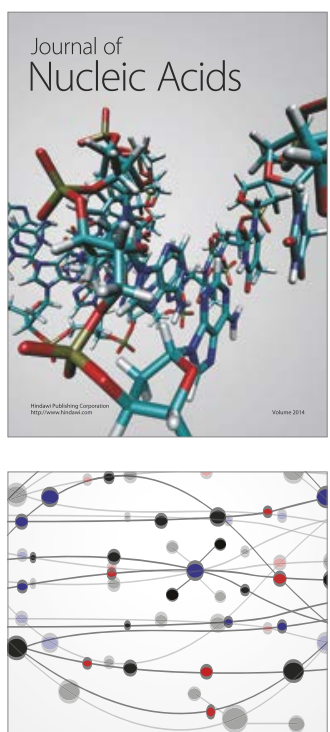

The Scientific World Journal

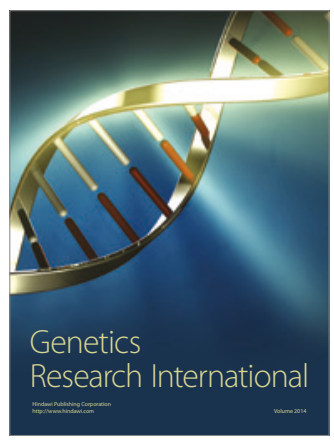

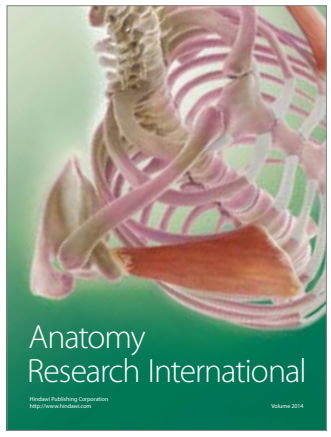

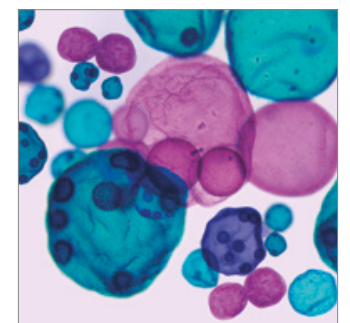

International Journal of Microbiology
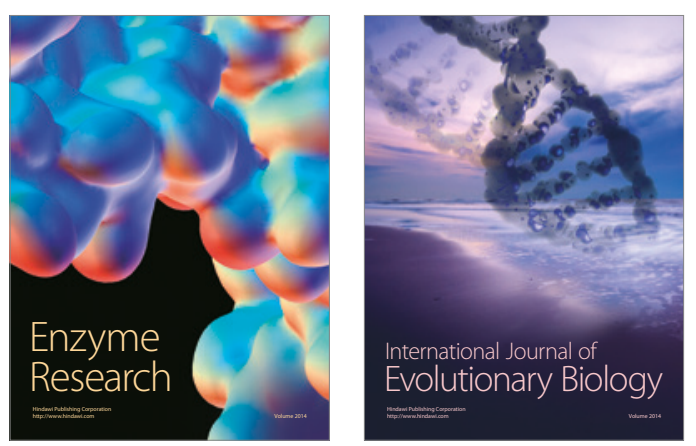
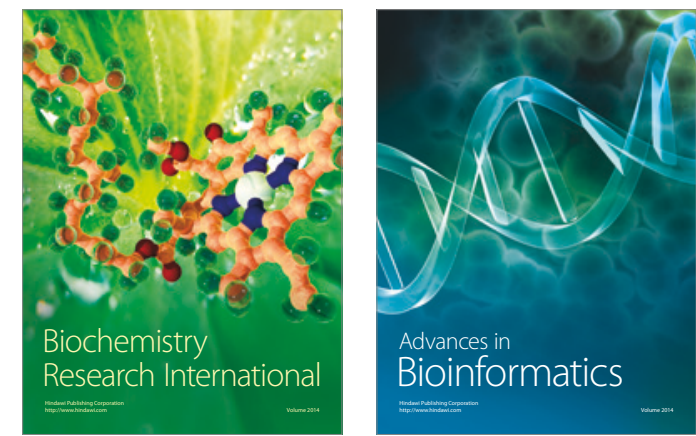

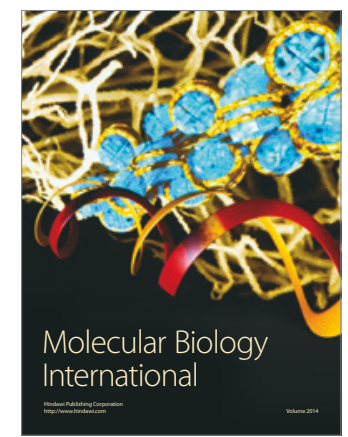

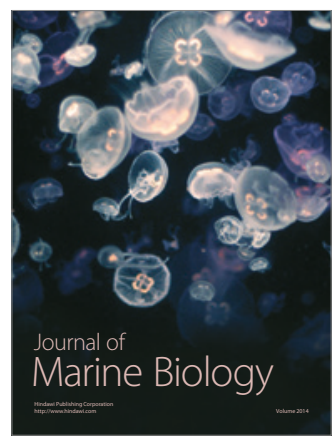

